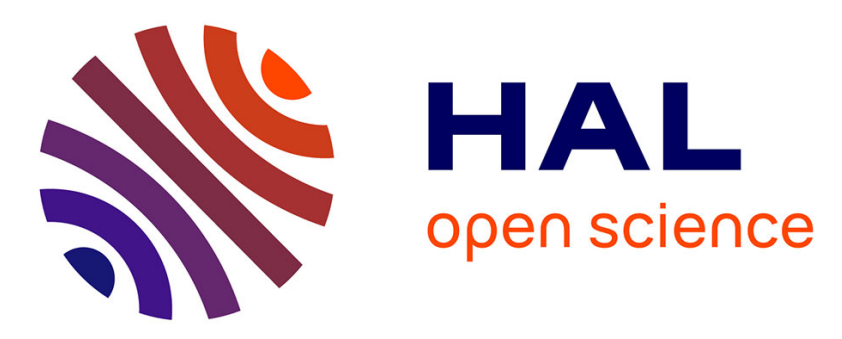

\title{
A three step supercritical process to improve the dissolution rate of Eflucimibe
}

Élisabeth Rodier, Hubert Lochard, Martial Sauceau, Jean-jacques

Letourneau, Bernard Freiss, Jacques Fages

\section{To cite this version:}

Élisabeth Rodier, Hubert Lochard, Martial Sauceau, Jean-jacques Letourneau, Bernard Freiss, et al.. A three step supercritical process to improve the dissolution rate of Eflucimibe. European Journal of Pharmaceutical Sciences, 2005, 26 (2), pp.184-193. 10.1016/j.ejps.2005.05.011 . hal-01668421

\section{HAL Id: hal-01668421 \\ https://hal.science/hal-01668421}

Submitted on 15 Mar 2018

HAL is a multi-disciplinary open access archive for the deposit and dissemination of scientific research documents, whether they are published or not. The documents may come from teaching and research institutions in France or abroad, or from public or private research centers.
L'archive ouverte pluridisciplinaire $\mathbf{H A L}$, est destinée au dépôt et à la diffusion de documents scientifiques de niveau recherche, publiés ou non, émanant des établissements d'enseignement et de recherche français ou étrangers, des laboratoires publics ou privés. 


\title{
A three step supercritical process to improve the dissolution rate of Eflucimibe
}

\author{
Elisabeth Rodier $^{\mathrm{a}, *}$, Hubert Lochard $^{\mathrm{a}, \mathrm{b}}$, Martial Sauceau ${ }^{\mathrm{a}}$, Jean-Jacques Letourneau ${ }^{\mathrm{a}}$, \\ Bernard Freiss ${ }^{b}$, Jacques Fages ${ }^{a}$ \\ a Ecole des Mines d'Albi-Carmaux, LGPSD-UMR CNRS 2392, 81013 Albi, France \\ b Institut de Recherche Pierre Fabre, BP 92, 81603 Gaillac, France
}

\begin{abstract}
The aim of this study is to improve the dissolution properties of a poorly-soluble active substance, Eflucimibe by associating it with $\gamma$ cyclodextrin. To achieve this objective, a new three-step process based on supercritical fluid technology has been proposed. First, Eflucimibe and cyclodextrin are co-crystallized using an anti-solvent process, dimethylsulfoxide being the solvent and supercritical carbon dioxide being the anti-solvent. Second, the co-crystallized powder is held in a static mode under supercritical conditions for several hours. This is the maturing step. Third, in a final stripping step, supercritical $\mathrm{CO}_{2}$ is flowed through the matured powder to extract the residual solvent. The coupling of the first two steps brings about a significant synergistic effect to improve the dissolution rate of the drug. The nature of the entity obtained at the end of each step is discussed and some suggestions are made as to what happens in these operations. It is shown the co-crystallization ensures a good dispersion of both compounds and is rather insensitive to the operating parameters tested. The maturing step allows some dissolution-recrystallization to occur thus intensifying the intimate contact between the two compounds. Addition of water is necessary to make maturing effective as this is governed by the transfer properties of the medium. The stripping step allows extraction of the residual solvent but also removes some of the Eflucimibe which is the main drawback of this final stage.
\end{abstract}

Keywords: Supercritical fluid; $\gamma$-Cyclodextrin; Eflucimibe; Solid dispersion; Inclusion complex

\section{Introduction}

Improving the dissolution properties of a poorly soluble active substance is a major concern of the pharmaceutical industry. It implies increasing dissolution rates and improving permeation through biological membranes. Eflucimibe is typical of these non-soluble molecules. Its chemical formula is $\mathrm{C}_{29} \mathrm{H}_{43} \mathrm{NO}_{2} \mathrm{~S}$ ( $S$-enantiomer of $2^{\prime}, 3^{\prime}, 5^{\prime}$-trimethyl-4'hydroxy- $\alpha$-dodecylthio-phenylacetanilide) with a chemical

Abbreviations: AUC, area under the curve; CD, cyclodextrin; DMSO, dimethylsulfoxide; DSC, differential scanning calorimetry; GPC, gas phase chromatography; HPLC, high performance liquid chromatography; NMR, nuclear magnetic resonance; RT, room temperature; SAS, supercritical antisolvent; SDS, sodium dodecyl sulfate

* Corresponding author. Tel.: +33 563493 153; fax: +33 563493025 .

E-mail address: rodier@enstimac.fr (E. Rodier). structure as shown on Fig. 1 (Junquero et al., 2001). It displays hypocholesterolemic properties inhibiting acyl-coenzyme A: cholesterol acyltransferase (ACAT), thus leading to lower serum cholesterol concentration.

Supercritical particle generation processes are a new and efficient route for improving the bioavailability of pharmaceutical active compounds (Fages et al., 2004). In a previous paper, we have shown that the supercritical antisolvent process (SAS) can improve the dissolution rate of Eflucimibe by a tenfold increase in the specific surface area of the powder (Lochard et al., 2002). This improvement has however proved to be insufficient; therefore an association with cyclodextrins has been investigated.

Cyclodextrins (CD) are a family of cyclic oligosaccharides which can form inclusion complexes with large organic molecules (Stella and Rajewski, 1997), thus improving their 


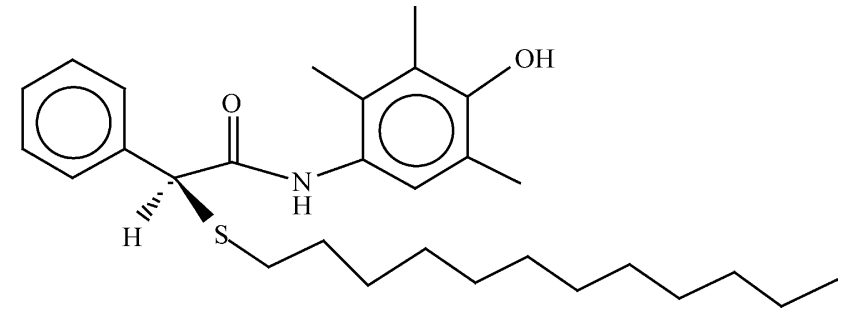

Fig. 1. Formula of Eflucimibe.

dissolution rate. The most common are the $\alpha-, \beta-$, and $\gamma$ cyclodextrins formed by, respectively, six, seven and eight glucose units. They are of the form of a truncated cone with a hydrophilic outer surface containing a hydrophobic cavity into which a drug can be encased to give a non-covalent bonded inclusion complex either in a solid phase or in an aqueous solution (Cabral Marques, 1994). This complexforming process is equivalent to a molecular encapsulation.

In aqueous solutions, the complex formation occurs by a process in which water molecules located inside the cavity are replaced by the whole drug molecule or some lipophilic structure of the molecule, thus lowering the energy of the system (Loftsson and Masson, 2001). Many characterization techniques can be used to contribute to proofs of the complexation. Mechanisms of solid phase inclusion have been less elucidated and the characterization of the complexes formed is less obvious. Solid complexes have commonly been analysed by differential scanning calorimetry (DSC) (Giordano et al., 2001) and they can also be analysed by infrared (IR) or X-ray spectroscopy. However, none of these three techniques have given undisputable evidence of the existence of a complex. They can only deliver pieces of information about interacting molecules suggesting a new entity, which may be more generally a solid dispersion. The best evidence of inclusion in solid phase might be given by nuclear magnetic resonance (NMR) analysis or by a differential solubility method (Van Hees et al., 2002).

Hence, one has to be cautious when characterizing a drug$\mathrm{CD}$ solid mixture, because as in a physical mixture there is no effective chemical interaction between the different components and their characteristics remain unchanged. A solid dispersion implies an intimate contact between the components to generate interaction between them (Yalkowsky, 1999). Their characteristics are thus changed: the melting point of a component may be decreased and its solubility increased. Besides, a solid solution is a mixture at the molecular scale. Usually, the miscibility (especially considering organic compounds) between compounds is partial and a solid solution is composed of one component in small quantity dispersed into the other (Craig, 2002). An inclusion complex is, therefore, a specific case of a solid dispersion in which the active substance is dispersed at the molecular level and included in CD cavities.

Several techniques have been used for the preparation of solid complexes. These include kneading, freeze drying or grinding but they are time and energy consuming (Gil et al., 2004). Supercritical carbon dioxide $\left(\mathrm{SC} \mathrm{CO}_{2}\right)$ is suggested as a new complexation medium due to its properties of improved mass transfer and increased solvating power. Different supercritical fluid techniques can be applied depending on the solubility of the guest molecule: extraction and percolation through a CD packed bed (Charoenchaitrakool et al., 2002), co-crystallization by SAS process (Foster et al., 2002) or complexation using a static method (Van Hees et al., 1999).

In the present study, we have applied such processes to Eflucimibe by combining the two last processes and complementing them by adding a final stripping step in order to extract residual solvent. Here, we discuss this new process which comprises three consecutive steps, a co-crystallization

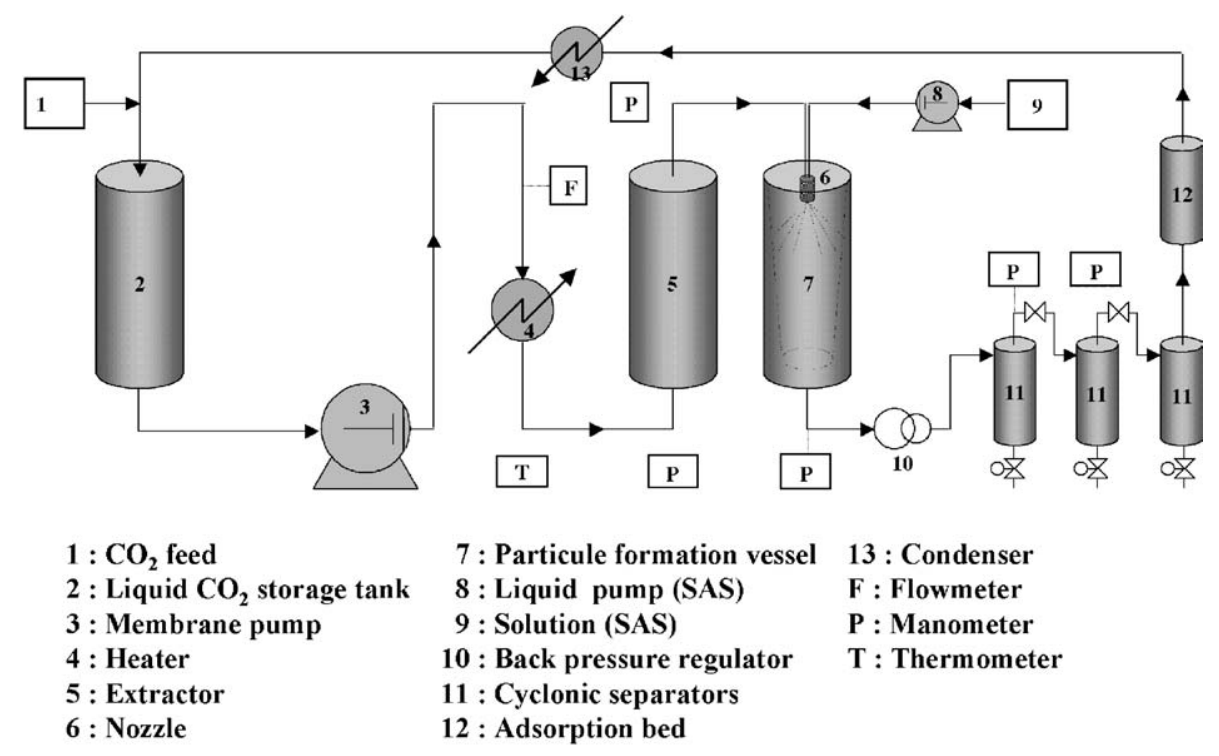

Fig. 2. Experimental set-up. 
performed in a SAS configuration, a batch step where the powder is held for a certain time in supercritical $\mathrm{CO}_{2}$, named the maturing step and finally a solvent stripping step. In addition, we have investigated the nature of the entity obtained.

\section{Experimental set-up, materials and methods}

\subsection{The experimental set up and the different configurations}

The experiments were carried out in a multifunctional pilot plant (Separex Champigneulles, France). A flowsheet of the apparatus is shown on Fig. 2. Carbon dioxide is cooled and stored in a liquid $\mathrm{CO}_{2}$ storage tank (2). It is circulated and pressurized by a membrane pump (Lewa, Germany) (3). Compressed $\mathrm{CO}_{2}$ then passes through a heat exchanger (4) and becomes supercritical.

For the SAS experiments, dimethylsulfoxide (DMSO) was used as the solvent and the antisolvent was $\mathrm{CO}_{2} \cdot \gamma-\mathrm{CD}$ and Eflucimibe were both dissolved in DMSO. This solution was injected into the $\mathrm{CO}_{2}$ stream coming from (5) by means of a HPLC pump (8) (Gilson, USA). Both flows were mixed in the mixing chamber of the nozzle (Spraying System, France), and the resulting mixture was sprayed into the expansion vessel (7). The powder formed was collected in a Teflon ${ }^{\circledR}$ porous bag placed in the expansion vessel (7). Then, the $\mathrm{CO}_{2}$-solvent mixture was depressurized (10) and separated in cyclonic separators (11). After purification by passage through a bed of activated carbon (12) and cooling (13), the condensed $\mathrm{CO}_{2}$ was recycled to the liquid $\mathrm{CO}_{2}$ storage tank (2).

In the batch step configuration, $7 \mathrm{~g}$ of Eflucimibe/CD powder (with a molar ratio of $1 / 2$ ) were wetted by $2.33 \mathrm{~g}$ of ultrapure water (corresponding to 25 mass $\%$ of total powder) and placed in the 21 extraction vessel (5). The vessel was filled with supercritical $\mathrm{CO}_{2}$ at the desired pressure and temperature and left for several hours without any agitation. The vessel was then slowly depressurized and the powder removed.

During the solvent stripping step, supercritical $\mathrm{CO}_{2}$ was run for two hours through the powder contained in a stainless steel basket (7). Experimental conditions are given in Table 1 .

\subsection{Materials}

$\mathrm{CO}_{2}$ (purity $99.995 \%$ ) was supplied by Air Liquide S.A., DMSO (purity $>99 \%$ ) was obtained from Aldrich. $\gamma$-CD with an initial mass water content of $8.7 \%$ was supplied by Wacker (Cavamax W8 pharma). Eflucimibe, the active compound (MW $=469.73 \mathrm{~g} / \mathrm{mol}$ ) was provided by Pierre Fabre Laboratories, Gaillac, France (Ribet et al., 2002).

\subsection{Characterization}

The powders obtained were characterized by an environmental scanning electron microscope XL30 ESEM FEG, (Philips Netherlands).
Table 1

Experimental conditions of the three-step process basic case and varying parameters

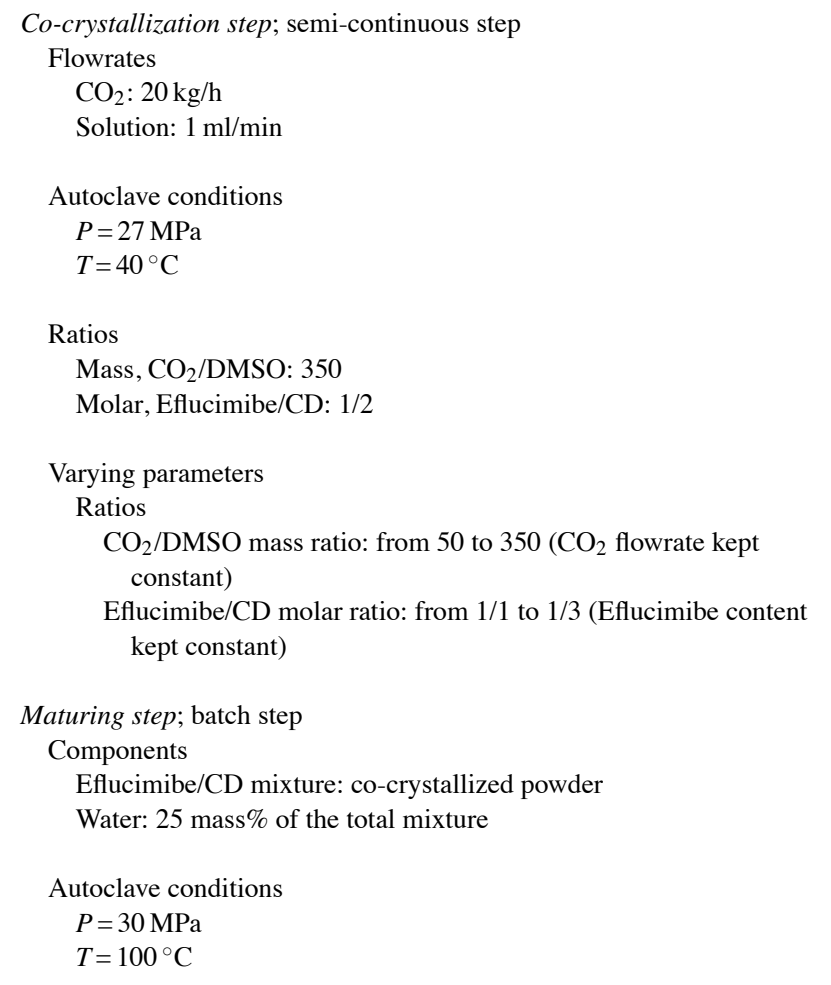

Operating time: $6 \mathrm{~h}$

Varying parameters

Eflucimibe/CD mixture: different physical mixtures or co-crystallized mixture

Operating time: from 1 to $16 \mathrm{~h}$

Stripping step; semi-continuous step

$\mathrm{CO}_{2}$ flowrate: $20 \mathrm{~kg} / \mathrm{h}$

Autoclave conditions

$P=27 \mathrm{MPa}$

$T=65^{\circ} \mathrm{C}$

Operating time: $2 \mathrm{~h}$

Varying parameters

Autoclave conditions

$P$ : from 10 to $30 \mathrm{MPa}$

T: 40 or $65^{\circ} \mathrm{C}$.

The composition of the powder obtained was determined after each step. Eflucimibe content was measured by HPLC, residual DMSO content by GPC and water content with a Karl Fisher titrator. $\gamma$-CD content was then deduced from all these results. The HPLC had a C8 column, (Lichrospher $60 \mathrm{RP}$-select B, Merck), $25 \times 0.4 \mathrm{~cm}$ packed with $5 \mu \mathrm{m}$ particles. The mobile phase was acetonitrile (volume percentage of $82 \%$ ) and purified water (volume percentage of $18 \%$ ), with a flow rate of $1 \mathrm{ml} / \mathrm{min}$. The detector was a UV spectrophotometer set at $220 \mathrm{~nm}$. The GPC had a column DB624, polycyanophenylsiloxane 6\%-polydimethylsiloxane 
Table 2

Characteristics of the co-crystallized powder

\begin{tabular}{ccll}
\hline & $\begin{array}{l}\text { Mean } \\
\text { value }\end{array}$ & $\begin{array}{l}\text { Standard } \\
\text { deviation, } \\
\text { homogeneity }\end{array}$ & $\begin{array}{l}\text { Standard } \\
\text { deviation, } \\
\text { reproducibility }\end{array}$ \\
\hline $\begin{array}{c}\text { Eflucimibe mass } \\
\text { content }(\%)\end{array}$ & 11.4 & 0.5 & 0.5 \\
$\begin{array}{c}\text { DMSO mass } \\
\text { content (\%) }\end{array}$ & 4.9 & 0.2 & 0.8 \\
$\begin{array}{c}\text { Water mass } \\
\text { content }(\%)\end{array}$ & 6.8 & & 0.8 \\
$\begin{array}{c}\text { Dissolved drug } \\
\text { concentration at } \\
2 \mathrm{~h}(\mu \mathrm{g} / \mathrm{ml})\end{array}$ & 105.1 & & 3.0 \\
\hline
\end{tabular}

$94 \% 30 \mathrm{~m} \times 0.32 \mathrm{~mm}$ with a film thickness of $1.8 \mu \mathrm{m}$. The temperature programme was; $40^{\circ} \mathrm{C}$ for $5 \mathrm{~min}$, then rose to $50{ }^{\circ} \mathrm{C}$ at a rate of $2{ }^{\circ} \mathrm{C} / \mathrm{min}$, then to $95^{\circ} \mathrm{C}$ at a rate of $5^{\circ} \mathrm{C} / \mathrm{min}$, then to $180^{\circ} \mathrm{C}$ at a rate of $10^{\circ} \mathrm{C} / \mathrm{min}$ and finally set to $180^{\circ} \mathrm{C}$ for $5 \mathrm{~min}$. The detector was a FID set at $250^{\circ} \mathrm{C}$. Eflucimibe, DMSO and water contents are given in mass percentage of the total powder mixture.

In vitro dissolution studies were performed at $37 \pm 1{ }^{\circ} \mathrm{C}$ to estimate the improvement in dissolution rate. A mass of powder mixture containing $50 \mathrm{mg}$ of Eflucimibe was put into a $100 \mathrm{ml}$ erlenmeyer containing $50 \mathrm{ml}$ of aqueous solution containing sodium-dodecyl-sulfate $(5 \mathrm{w} / \mathrm{v} \%)$, and stirred with a magnetic stirrer at a speed of $400 \mathrm{rpm}$. Samples of $2 \mathrm{ml}$ of the suspension were removed at fixed time intervals so as not to modify the dissolving medium. They were filtered through a polypropylene membrane having a cut-off diameter of $0.45 \mu \mathrm{m}$. The concentration of dissolved drug, expressed in micrograms of Eflucimibe per ml of solution, was then measured by HPLC. In this way, the dissolution kinetics were established and the equilibrium solubility estimated after $20 \mathrm{~h}$ of dissolution. It should be noted that performing a dissolution test without adding any surfactant to the dissolving medium is impossible in our case due to the fact that the water solubility of Eflucimibe is undetectable (less than $4 \mu \mathrm{g} / \mathrm{ml}$ ). Besides, the release rates were not measured in sink conditions and do not strictly describe the intrinsic properties of the delivery system. However, all tests were performed under the same conditions and allowed us to compare the behaviour of the resulting three-step processed mixtures.

The DSC thermograms were performed with a PerkinElmer, DSC-7 calorimeter equipped with a thermal flux cell device. The DSC patterns of the samples (2-3 mg) were obtained between 40 and $140{ }^{\circ} \mathrm{C}$ at a heating rate of $5^{\circ} \mathrm{C} / \mathrm{min}$ under a $\mathrm{N}_{2}$ gas stream. By integrating the melting peak of the crystalline drug in DSC thermograms, and knowing the total drug content independently, it is possible to calculate the amount of non-crystalline Eflucimibe according to:
$\Delta H_{\mathrm{f}}$ being the melting enthalpies calculated on DSC thermograms, in $\mathrm{J} / \mathrm{g}$.

This non-crystalline part corresponds to the drug, which could no longer be visualized on the DSC thermograms, i.e. the drug molecules interacting with CD (usually assumed to be complexed molecules) and possibly, amorphous aggregates dispersed among CD matrix. Thermal analysis has been widely used to characterize inclusion complexes, especially to assess their stoichiometry (Giordano et al., 2001). It must, however, be complemented by other analyses, when available, to demonstrate drug-CD interaction but here it allows us to evaluate the evolution of the mixture throughout the process.

\section{Main results}

\subsection{Preliminary characterization of materials}

It has been previously established that Eflucimibe is poorly soluble in supercritical $\mathrm{CO}_{2}$ (mole fraction of $5.71 \times 0^{-7}$ at $27.4 \mathrm{MPa}$ and $35^{\circ} \mathrm{C}$ ) (Sauceau et al., 2004) and insoluble in water. On a DSC thermogram, the onset temperature giving the melting point of the Eflucimibe was at $T_{\text {melting }}=128.9 \pm 0.7^{\circ} \mathrm{C}$ and the heat of fusion was $\Delta H_{\text {melting }}=76 \pm 1 \mathrm{~J} / \mathrm{g}$. The solubility was estimated to be $100 \pm 10 \mu \mathrm{g} / \mathrm{ml}$, according to the dissolution test given above. This solubility was unchanged for a physical mixture of Eflucimibe and $\gamma$-CD (Fig. 6) The DSC curve (Fig. 5(a)) of this physical mixture showed a broad endothermic peak between 50 and $100{ }^{\circ} \mathrm{C}$ corresponding to the water loss of the $\gamma$-CD followed by endothermic peaks corresponding to conformational transition of the Eflucimibe at $111^{\circ} \mathrm{C}$ and to the fusion of the Eflucimibe close to $129^{\circ} \mathrm{C}$, respectively. The initial drug powder is a rather pure polymorphic form.

Furthermore, we can find in the literature that the $\gamma$-CD is insoluble in supercritical $\mathrm{CO}_{2}$ and its solubility in water is $23.2 \mathrm{~g} / 100 \mathrm{ml}$, RT (Giordano et al., 2001). The solubility of water in supercritical $\mathrm{CO}_{2}$ is $4.625 \mathrm{~g} / \mathrm{l}$ at $30 \mathrm{MPa}$ and $85^{\circ} \mathrm{C}$ or $1.79 \mathrm{~g} / 1$ at $30 \mathrm{MPa}$ and $50^{\circ} \mathrm{C}$ (Wiebe and Gaddy, 1941). One has to be careful that these last solubilities are for free pure water.

SEM microscope pictures of SAS-processed Eflucimibe and of $\gamma$-CD are given on Fig. 3(a) and (b).

\subsection{The co-crystallization step}

This step is conducted according to a standard SAS configuration as previously described for crystallizing Eflucimibe alone (Lochard et al., 2002).

$$
\begin{aligned}
& \text { non-crystalline drug content }=1-\frac{\text { crystalline drug content in treated mixture }}{\text { total drug content in treated mixture }} \\
& \text { non-crystalline drug content }=1-\frac{\Delta H_{\mathrm{f}_{\text {crystalline drug in mixture }}} / \Delta H_{\mathrm{f}_{\text {pure drug }}}}{(\text { drug weight } / \text { mixture weight })_{\text {HPLC measured }}}
\end{aligned}
$$




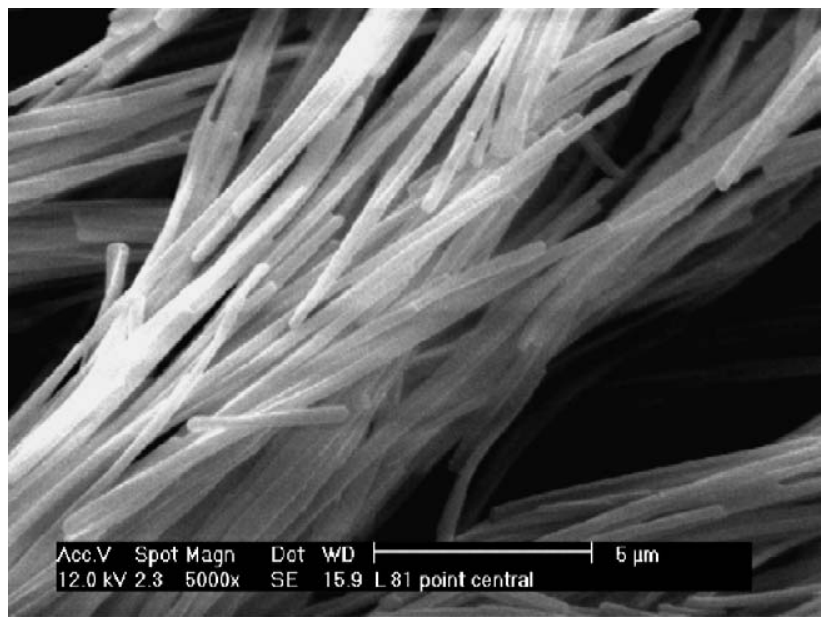

(a)

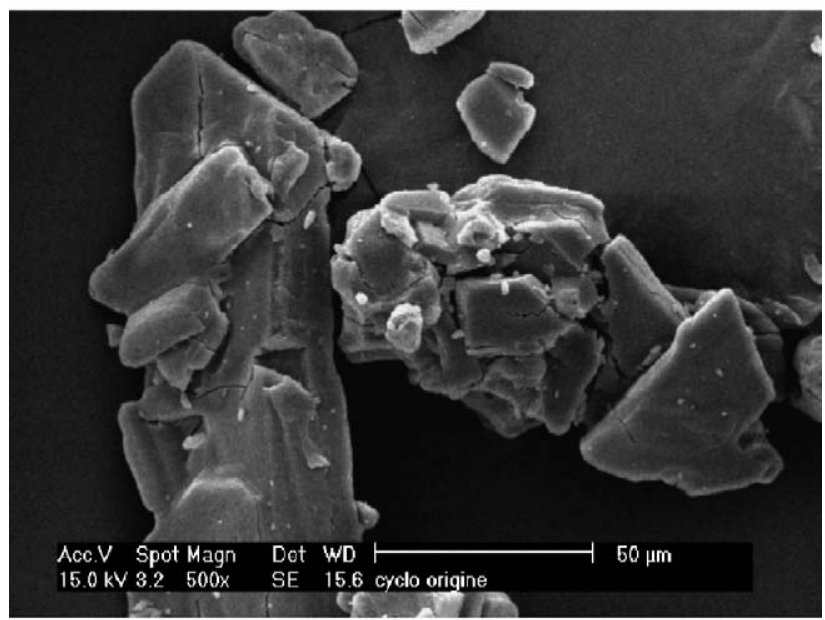

(b)

Fig. 3. ESEM pictures of SAS processed Eflucimibe (a), and of raw Cavamax $\gamma-\mathrm{CD}(\mathrm{b})$

The powder resulting from the co-crystallization step is shown on Fig. 4(a). Large CD particles and drug fibres deposited on them can easily be distinguished. Measured characteristics of this powder are given in Table 2. The composition homogeneity of the powder was tested by characterizing four samples taken from the same experiment at different positions in the porous bag. The reproducibility of the experimental procedure was tested by performing the same experiment three times. This showed that the powder obtained can be considered to be homogeneous and that the experiments were reasonably reproducible.

The Eflucimibe melting temperature in the physical mixture of Fig. $5(\mathrm{a})$ is $128.9^{\circ} \mathrm{C}$. For the co-crystallized powder, we observed a melting temperature of $126.0 \pm 0.6^{\circ} \mathrm{C}$. This latter result is a mean value calculated from all the 29 co-crystallization experiments performed. In addition, a part of the Eflucimibe contained in the mixture after cocrystallization is not visible by DSC corresponding to the non-crystalline part defined above.

After this step, the dissolved drug concentration was higher than that of the physical mixture with the same profile

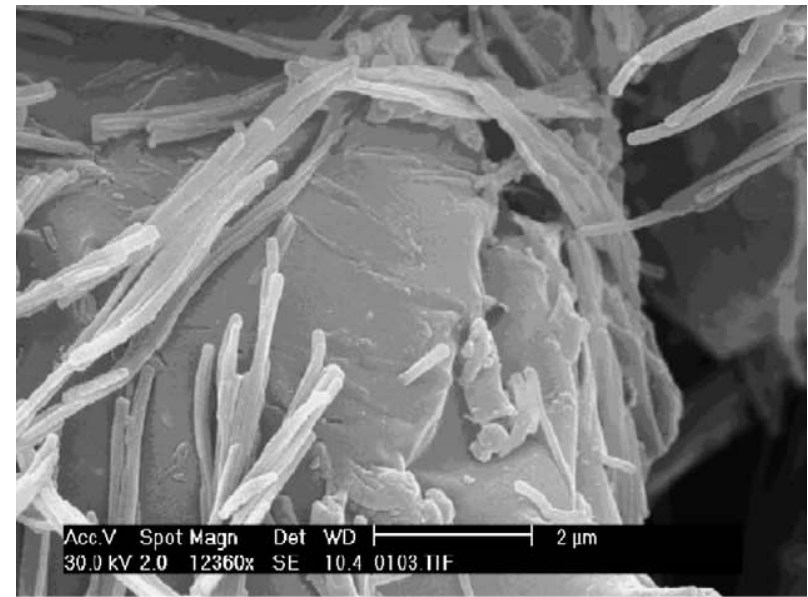

(a)

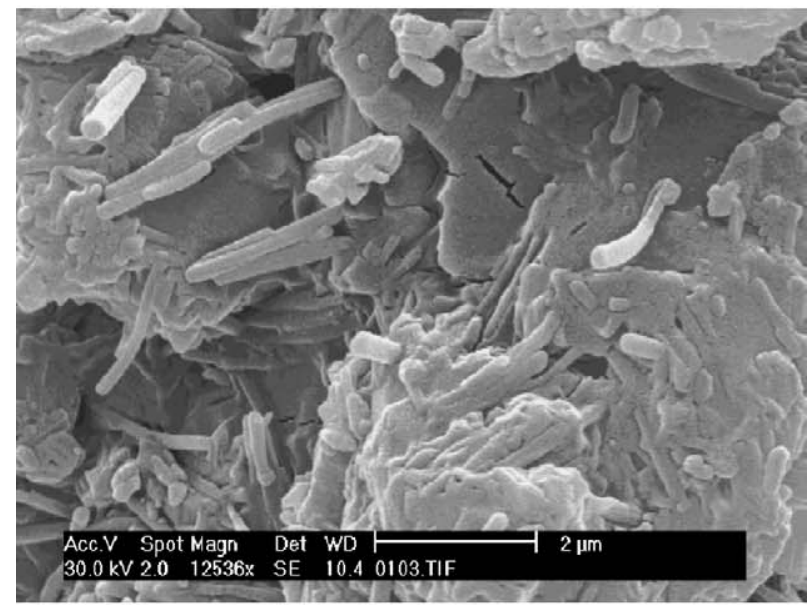

(b)

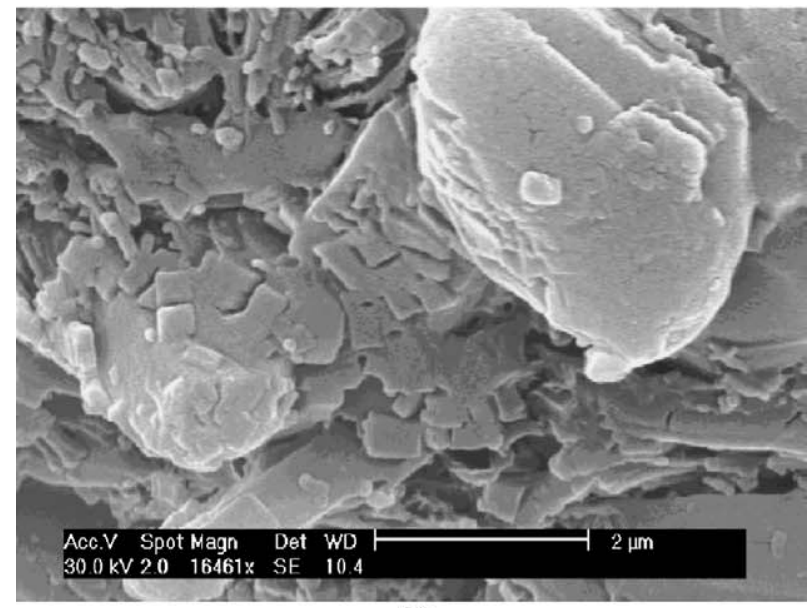

(c)

Fig. 4. SEM pictures of $\gamma$-cyclodextrin/Eflucimibe after co-crystallization (a); after co-crystallization and maturing step (b); and after final stripping step (c).

(Fig. 6(b)). It was no longer correlated to the specific surface of the powder as was the case with the SAS-processed Eflucimibe alone (Lochard et al., 2002) but was correlated to the presence of CD. This presence renders this step insensitive to the main operating parameters. For instance, the mass 


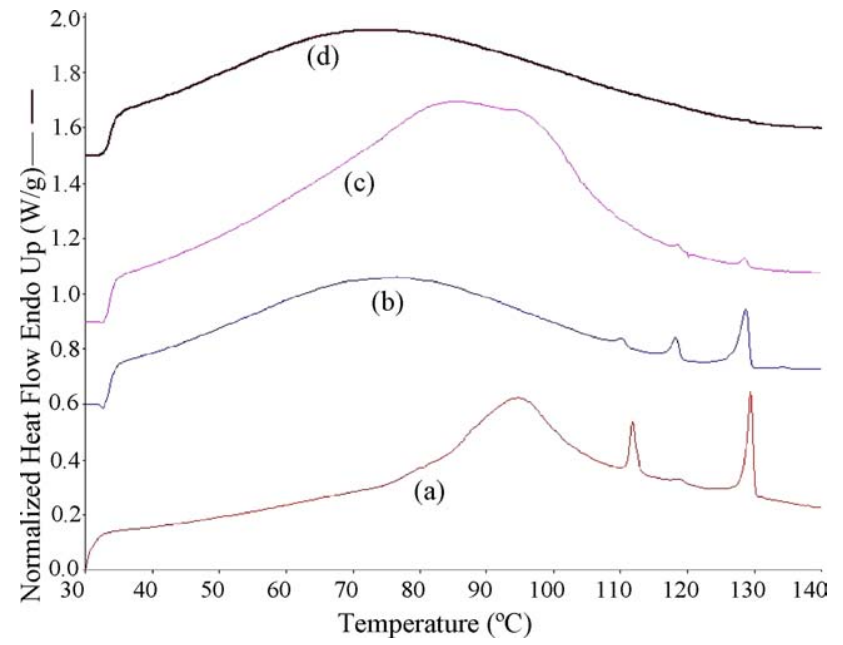

Fig. 5. Typical DSC curve physical mixture (a); co-crystallized powder (b); powder after co-crystallization and maturing step (c); and powder after cocrystallization, maturing step and stripping (d).

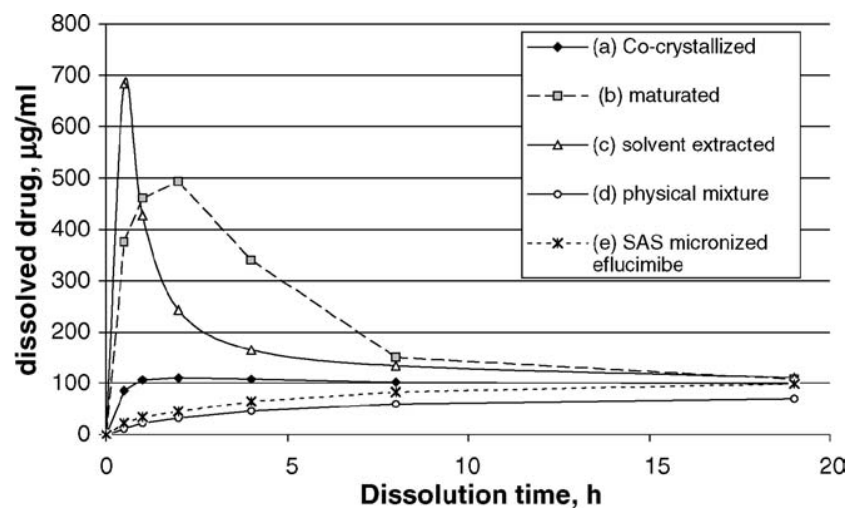

Fig. 6. Dissolution curves of co-crystallized powder (a); powder after cocrystallization and maturing step (b); powder after co-crystallization, maturing step and stripping (c); physical mixture (d); and SAS micronized Eflucimibe (e).

ratio $\mathrm{CO}_{2} / \mathrm{DMSO}$ applied during the co-crystallization SAS experiment, was varied between 50 and 350 , but had no effect on the composition and dissolved drug concentration of the resulting powder (Fig. 7). On the contrary, decreasing the molar ratio of Eflucimibe to $\mathrm{CD}$ in the initial mixture from $1 / 1$ to $1 / 3$ increased the drug crystallization yield from 40 to $70 \%$ (w/w) (Fig. 8). This yield is defined as the ratio between

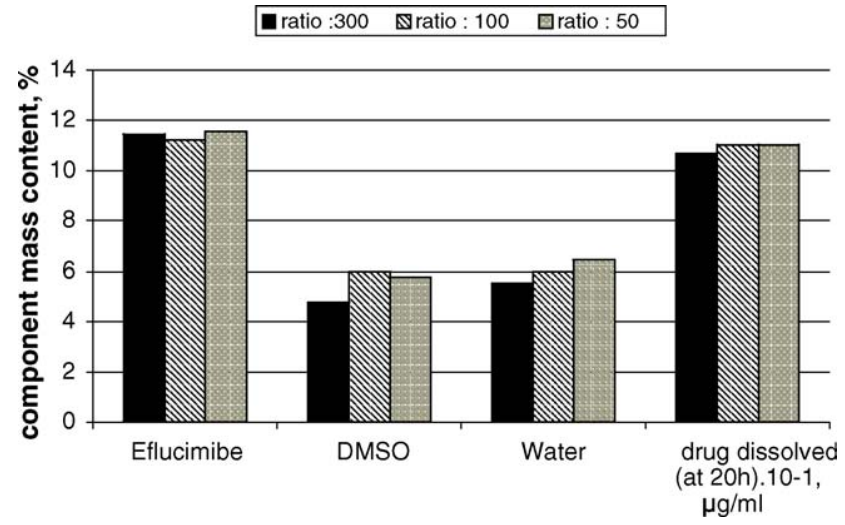

Fig. 7. Co- crystallization step: component mass content, $\%$ (errors \pm 0.6 for Eflucimibe, \pm 0.7 for DMSO and water) and dissolved drug concentration, $\mu \mathrm{g} / \mathrm{ml} \times 10^{-1}$ (error \pm 0.4 ), in function of the solvent/antisolvent ratio.

the mass of powder formed and the mass of powder initially dissolved in DMSO.

\subsection{The maturing step}

After the static step and as seen on Fig. 4(b) the drug fibres are not so clearly distinguishable from CD particles, and these fibres seem to be shorter. Furthermore, we can observe only a very small Eflucimibe melting peak on the DSC thermogram (Fig. 5(c)) and the modification of the drug dissolution profile on which a peak appears with a maximum value as high as $500 \mu \mathrm{g} / \mathrm{ml}$ (Fig. 6(c)).

The influence of $\mathrm{CO}_{2}$ density and viscosity is presented in Table 3. Here, $\mathrm{CO}_{2}$ density was evaluated with the Peng-Robinson EOS (Peng and Robinson, 1976), the viscosity with the Altunin correlation (Altunin and Sakhabetdinov, 1972). Eflucimibe solubility in supercritical $\mathrm{CO}_{2}$ was calculated by using the density-based correlation and the associated parameters proposed by Sauceau et al. (2003). It appears that non-crystalline drug content increases - as well as the dissolved drug concentration - when $\mathrm{CO}_{2}$ density and viscosity decrease and when temperature increases. The maturing step is limited by mass transfer and enhanced by a low $\mathrm{CO}_{2}$ solvent power. In addition, the influence of the operating time of this static step has been studied. A classical saturation-shape evolution was noticed: i.e. up to $6 \mathrm{~h}$, the powder composition

Table 3

Effect of the maturing step on-crystalline content and dissolved drug concentration of the Eflucimibe obtained as a function of $\mathrm{CO}_{2}$ density and viscosity $\mathrm{CO}_{2}$ solubility of Eflucimibe

\begin{tabular}{|c|c|c|c|c|c|c|}
\hline$T\left({ }^{\circ} \mathrm{C}\right)$ & $P(\mathrm{MPa})$ & $\rho\left(\mathrm{kg} / \mathrm{m}^{3}\right)$ & $\mu(\mathrm{Pas})$ & $\begin{array}{l}S_{\text {Eflucimibe } / \mathrm{CO}_{2}} \\
\left(\times 10^{7}, \text { mole fraction }\right)\end{array}$ & $\begin{array}{l}\text { Non-crystalline } \\
\text { Eflucimibe (mass\%) }\end{array}$ & $\begin{array}{l}\text { Dissolved drug concentration } \\
\text { at } 2 \mathrm{~h}(\mu \mathrm{g} / \mathrm{ml})\end{array}$ \\
\hline 100 & 10 & 278 & $2.40 \times 10^{-5}$ & 54 & 98.8 & 678.4 \\
\hline 40 & 10 & 564 & $3.78 \times 10^{-5}$ & 1 & 88.5 & 522.9 \\
\hline 100 & 30 & 644 & $4.70 \times 10^{-5}$ & 571 & 88.6 & 503 \\
\hline 80 & 30 & 734 & $5.41 \times 10^{-5}$ & 169 & 84.1 & 596.5 \\
\hline 40 & 20 & 830 & $6.16 \times 10^{-5}$ & 5 & 82.3 & 487.9 \\
\hline 60 & 30 & 831 & $6.26 \times 10^{-5}$ & 46 & 83.2 & 499 \\
\hline
\end{tabular}


Table 4

Maturing step, dissolved drug concentrations and specific surface areas as a function of the initial mixture

\begin{tabular}{|c|c|c|c|}
\hline $\begin{array}{l}\text { Eflucimibe } \\
\text { Cyclodextrin }\end{array}$ & $\begin{array}{l}\text { Initial powder } \\
\text { Initial Cavamax }\end{array}$ & $\begin{array}{l}\text { SAS treated } \\
\text { SAS treated }\end{array}$ & $\begin{array}{l}\text { Co-crystallized } \\
\text { Co-crystallized }\end{array}$ \\
\hline BET specific surface of the mixture $\left(\mathrm{m}^{2} / \mathrm{g}\right)$ & 2.3 & 17.1 & 8.6 \\
\hline BET specific surface of the Eflucimibe alone $\left(\mathrm{m}^{2} / \mathrm{g}\right)$ & 7.5 & 54 & - \\
\hline $\begin{array}{l}\text { Dissolved drug concentration at } 2 \mathrm{~h} \text { of the mixture, just } \\
\text { after mixing the powders }(\mu \mathrm{g} / \mathrm{ml})\end{array}$ & 19 & 69 & 100 \\
\hline $\begin{array}{l}\text { Dissolved drug concentration at } 2 \mathrm{~h} \text { of the mixture, after } \\
\text { adding maturing water }(\mu \mathrm{g} / \mathrm{ml})\end{array}$ & 33 & 58 & 88 \\
\hline $\begin{array}{l}\text { Dissolved drug concentration at } 2 \mathrm{~h} \text { of the mixture, after } \\
\text { the maturing step }(\mu \mathrm{g} / \mathrm{ml})\end{array}$ & 141.6 & 150.3 & 670 \\
\hline
\end{tabular}

was modified and dissolution kinetics increased, whilst after $6 \mathrm{~h}$ both remained constant.

We have also studied the effect of the initial mixture composition. Three mixtures having the same mass composition were wetted, placed in the autoclave and submitted to the maturing step under the same arbitrary conditions (at $30 \mathrm{MPa}$, $100{ }^{\circ} \mathrm{C}$ for $16 \mathrm{~h}$ ). The first mixture was composed of the initial drug and $\mathrm{CD}$, the second mixture was of the initial drug and CD crystallized separately by SAS process and the third mixture contained the initial drug and CD co-crystallized by SAS. Table 4 shows the dissolved drug concentration after $2 \mathrm{~h}$ for each mixture at different stages: just after mixing, just after adding water, and after the static maturing step. This table also shows the specific surface area of the mixtures. Comparison of the first and the second mixtures before the static step confirms that the amount of dissolved drug increases with the specific surface area. Comparing the second and the third mixtures, it appears that the amount of dissolved drug is no longer correlated to the specific surface area. In addition, the static step enhances the dispersion of the drug into the $\mathrm{CD}$ matrix and thus increases the dissolved drug concentration in all cases. However, the improvement of the compound dissolution is significantly higher when co-crystallized powder is used. In conclusion, a strong synergistic effect is obtained by coupling the co-crystallization and the static steps (Fig. 8).

Fig. 9 shows the dissolved drug content after $2 \mathrm{~h}$, as a function of non-crystalline drug ratio for all the co-

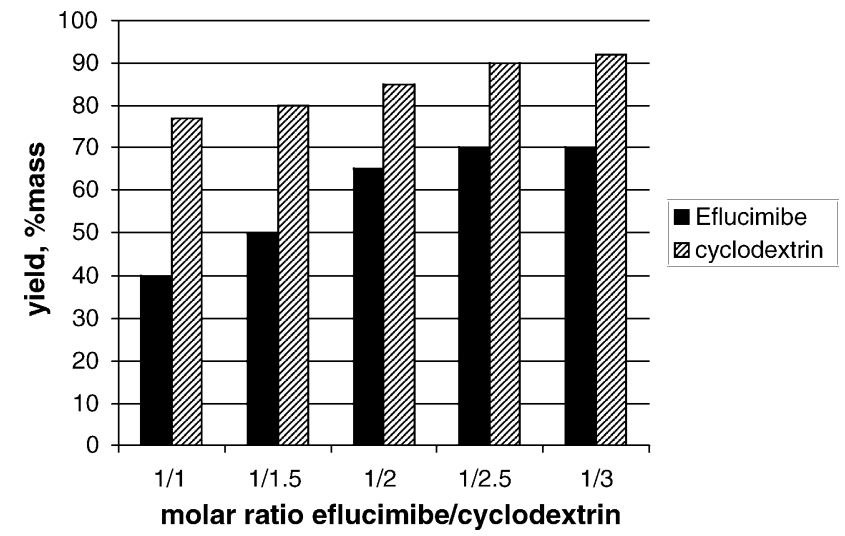

Fig. 8. Co-crystallization step, component yield as a function of the molar ratio introduced. crystallization and co-crystallization/static step experiments, which were performed. A linear correlation is seen between the dissolved co-crystallized/maturated drug concentration and the non-crystalline amount of drug. Inversely, the dissolved drug concentration of the co-crystallized powder seems to be independent of the non-crystalline drug ratio.

Finally, an important point concerns the presence of water in the powder mixture. Experiments have shown that if no water is added in the maturing step there is no modification of the initial mixture. Hence, water is a crucial component. Furthermore, the addition of water to the mixture without performing the maturing step is not sufficient to improve the dissolution characteristics of the drug (Table 4).

\subsection{The stripping step}

The powder is observed to have a homogeneous aspect after the stripping step, (Fig. 4(c)). This can be correlated to the complete disappearance of the Eflucimibe melting peak (Fig. 5(d)) and to a sharper and higher dissolution peak (Fig. 6(d)). Fig. 10 shows the evolution of the content of DMSO, Eflucimibe and CD throughout the three steps of the

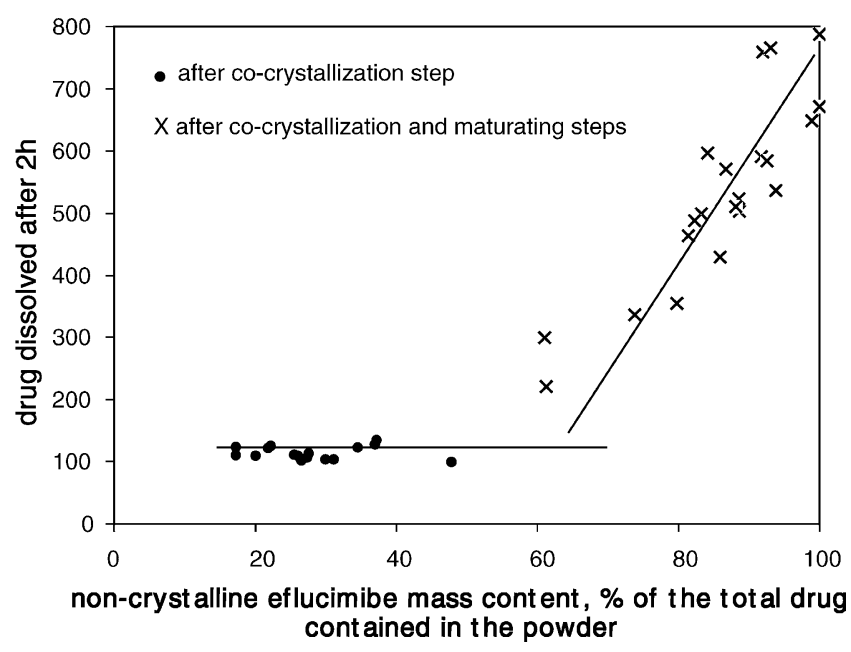

Fig. 9. Drug dissolved drug concentration at $2 \mathrm{~h}$ as a function of the ratio of non-crystalline drug. 


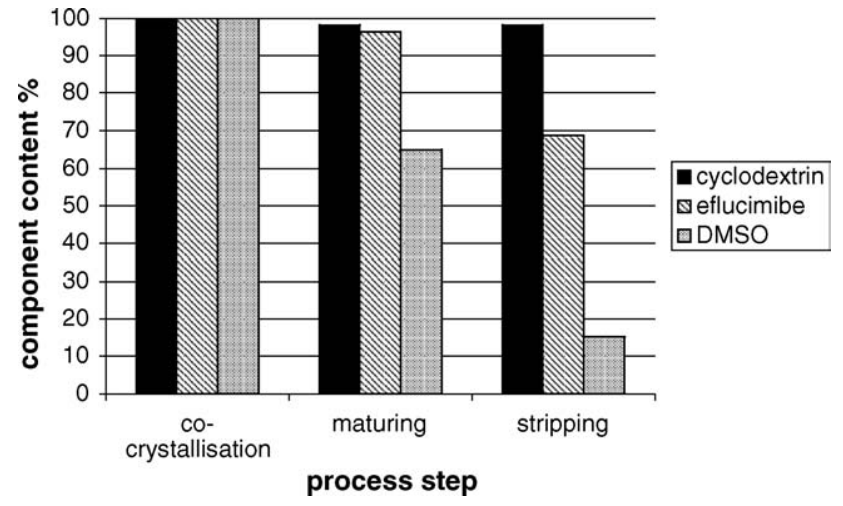

Fig. 10. Component content (in percentage of component content in cocrystallization step) through the three steps of the process.

process. The average solvent content of the powder obtained is about $10,000 \mathrm{ppm}$, which is twice the pharmaceutical standard for a class III solvent. The aim of the stripping step was to decrease the solvent content, but in fact, drug extraction also occurred whatever the experimental conditions. Decreasing the solvent below this threshold is possible, but an additional extraction of active substance will be unavoidable which is the main drawback of this step. However, it is the Eflucimibe not associated with the $\mathrm{CD}$, which was extracted. In addition, the stripping step also dehydrates the $\mathrm{CD}$. The water content falls from roughly 13 mass $\%$ to $2-3$ mass $\%$ during the stripping step. This explains the rapid increase in the initial dissolved drug concentration due to the enhanced hygroscopicity of the drug-CD mixture. The removal of water from the hydrated CD could result in void spaces in place of the removed molecules. Because of the structural weakness of the $\mathrm{CD}$ matrix it can easily be penetrated by water when performing a dissolution test, thus enhancing the initial dissolution rate (Yalkowsky, 1999).

\subsection{Dissolution kinetics}

The dissolution kinetics evolves in the following way. First, the dissolving medium diffuses into the CD matrix containing Eflucimibe. Then, Eflucimibe is dispersed into the dissolving medium and is temporarily stabilized into SDS micelles corresponding to the maximum dissolved drug concentrations on Fig. 6. Then follows a recrystallization of Eflucimibe leading back, after a sufficient period of time (at least $20 \mathrm{~h}$ ), to the solubility of pure Eflucimibe in this dissolving medium, (that is around $100 \mu \mathrm{g} / \mathrm{ml}$ ). According to this scenario, the increase in dissolved drug concentration does not correspond to a true dissolution of the active substance, but to the generation of a metastable colloidal dispersion of SDS micelles including drug. Finally, the acceleration of the dissolution kinetics after the stripping step may be due to the acceleration and amplification of the first dissolution step, that is the diffusion of the aqueous medium through the dehydrated CD matrix.

\section{The three-step process: nature and evolution of the obtained powder}

\subsection{The Eflucimibe/ $\gamma-C D$ mixture: previous studies}

Previous molecular modelling showed that a complex formation could occur in the case of this mixture (Gil, 2001). However, NMR analyses, performed in aqueous solutions (Ribet et al., 2002) concluded to the absence of this complex. In the solid state, X-Ray analyses showed that the diffractrogram of the maturated mixture was different from that corresponding to a physical mixture thus suggesting that a new entity was synthesized. In addition, the Eflucimibe melting peak partially disappeared on DSC thermograms. Therefore, although the entity obtained is different from a physical mixture, there is a lack of evidence for a true inclusion complex.

\subsection{Evolution of the mixture through the three steps}

The co-crystallized powder might be composed of two solid dispersions. Firstly, a dispersion of Eflucimibe in CD exhibiting no apparent peak on the DSC results since Eflucimibe would no longer be in a crystalline state. Secondly, some CD would be dispersed in the remaining crystalline Eflucimibe particles which would induce a decrease of the melting temperature compared to that of pure Eflucimibe as is seen on DSC thermograms. In addition, Fig. 9 shows that the dissolved drug concentration remains independent of the non-crystalline drug content. It seems that a minimum degree of dispersion of the drug-CD mixture is required to attain the maximum dissolved drug concentration of $100 \mu \mathrm{g} / \mathrm{ml}$. Beyond this dispersion threshold, the dissolution properties no longer evolve or this evolution is undetectable with our dissolution test. Moreover, Sertsou and co-workers claim that solid solutions can be formed by anti-solvent co-precipitation (Sertsou et al., 2002). Undergoing precipitation, plasticization and resulting high molecular mobility allow molecular rearrangement inducing the formation of a solid solution. If applied to the co-crystallized powder, this would mean that crystallization mechanisms are rather different from those involved in the case of pure Eflucimibe. In this latter case, nucleation was mainly homogeneous but it could be heterogeneous during co-crystallization, which could explain the insensitivity of the powder properties to the process parameters.

As for the maturated powder, the melting peak of Eflucimibe decreases from step to step along the process (see Fig. 5) and this decrease can be correlated to the increase of the dissolved drug concentration (see Fig. 9). The drug-CD mixture may no longer be a mere solid dispersion. Furthermore, the addition of water is a key-factor in this step. Water was added when preparing the powder mixture, and this acted as a solvent for the mixture thus dissolving more $\mathrm{CD}$ than Eflucimibe. Then, the mixture was put in the autoclave under static conditions and the maturing step began. A part of the 
water could then dissolve into supercritical $\mathrm{CO}_{2}$ while the other part could remain on the surface of the solid partially dissolving the CD. Note that the solubility of the water present in our autoclave, that is water saturated with dissolved CD and bound water on solid CD surface, may be less than the ones given in Section 3.1 which were for free water. The resulting supersaturation ratio, even if supersaturation is very low, can induce recrystallization of $\mathrm{CD}$. The way this $\mathrm{CD}$ recrystallizes could be driven by the minimization of the contact surface between powder and fluid, as in an Oswald ripening phenomenon (Mullin, 1992). For our batch system (contents of the autoclave) the variation of its free enthalpy, $G$, is:

$\mathrm{d} G=-S \mathrm{~d} T+V \mathrm{~d} P+\gamma^{\mathrm{S}} \mathrm{d} A$

$S$ being the entropy, $V$ the volume of the system, $\gamma^{\mathrm{S}}$ the interfacial tension of the solid, $A$ its surface area.

Once the temperature $T$ and the pressure $P$ are fixed, the free enthalpy can only be minimized by varying the contact surface between fluid and solid. A process of particle coarsening implies that when solid particles are surrounded by their own saturated solution there is a tendency for the smaller particles to dissolve and the solute to be deposited onto the larger particles. In addition, ripening implies a diffusion of solute molecules towards the solid surface, which may be favoured by an increase in temperature. This hypothesis implies that a certain degree of supersaturation is maintained at the solid surface, thus water has to remain partly on solid surface and $\mathrm{CO}_{2}$ solvent power has to remain low enough.

Small quantities of Eflucimibe dissolve in supercritical $\mathrm{CO}_{2}$, thus slightly decreasing the drug content in the mixture, which does not favour the formation of an interacting mixture. Once again, the solvent power of supercritical $\mathrm{CO}_{2}$ has to remain low enough.

Eventually, the stripping step may not modify the nature of the maturated mixture. As explained earlier, it dehydrates the powder, leading to an increase in the dissolved drug concentration, and it extracts free Eflucimibe not well dispersed with CD.

\section{Conclusion}

In order to enhance the dissolved drug concentration of Eflucimibe, a new process using supercritical $\mathrm{CO}_{2}$ and $\gamma-\mathrm{CD}$ is proposed which leads to the formation of a solid dispersion of Eflucimibe and $\gamma$-CD. This process comprises three steps: (1) a semi-continuous co-crystallization by a supercritical anti-solvent process generating a solid dispersion, (2) a batch maturing step during which the powder mixture evolves towards a more intimate mixture, and (3) a final semicontinuous stripping step where residual solvent is extracted with some Eflucimibe and water.

Co-crystallization by SAS ensures a very fine dispersion of the hydrophobic drug in the hydrophilic CD powder. The crystallization mechanisms seem to be different from previously studied SAS crystallization of pure Eflucimibe since the process parameters here have very little influence on this step. The main degree of freedom remains the way the antisolvent and the solution are contacted together, as is commonly admitted in SAS experiments.

The second or maturing step, in which the co-crystallized powder is wetted and is held under supercritical conditions for a few hours, leads to an interacting mixture with an enhanced dissolved drug concentration. This formation is favoured by a low $\mathrm{CO}_{2}$ density and therefore by a low solvent power. An increase in temperature, which enhances the molecule mobility in the supersaturated phase at the solid surface, may also be favourable. As for the mechanisms involved, it is suggested that water is a solvent for the mixture, which partially dissolves and recrystallises with a rearrangement of the compounds as in a ripening phenomenon, thus enhancing the dispersion of Eflucimibe into CD.

Finally, a stripping step extracts the residual solvent. A potential drawback of this step is the simultaneous extraction of some active substance. Therefore, it should be improved, for instance by studying the influence of the process parameters.

The main novelty of this process lies in the coupling of these three steps, exhibiting a strong synergistic effect in the improvement of the dissolved drug concentration of the drug. Such processed powder has been tested in animal studies (unpublished data) and shows a large and significant improvement in the in vivo bioavailability: it was multiplied by ten (considering the AUC) in dog studies.

\section{References}

Altunin, V., Sakhabetdinov, M., 1972. Viscosity of liquid and gaseous carbon dioxide at temperature $200-1300 \mathrm{~K}$ and pressure up to 1200 bars. Teploenergetika 8, 85-88.

Cabral Marques, H.M., 1994. Structure and properties of cyclodextrins. Inclusion complex formation. Rev. Port. Farm. XLIV (2), 7783.

Craig, D.Q.M., 2002. The mechanisms of drug release from solid dispersions in water-soluble polymers. Int. J. Pharm. 231, 131-144.

Charoenchaitrakool, M., Dehghani, F., Foster, N.R., 2002. Utilization of supercritical carbon dioxide for complex formation of ibuprofen and methyl-beta-cyclodextrin. Int. J. Pharm. 239, 103-112.

Fages, J., Lochard, H., Letourneau, J.-J., Sauceau, M., Rodier, E., 2004. Particle generation for pharmaceutical applications using supercritical fluid technology. Powder Technol. 141, 219-226.

Foster, N.R., Mammucari, R., Dehghani, F., 2002. Coprecipitation of pharmaceuticals using gas antisolvent technique. In: Besnard, M., Cansell, F. (Eds.), Proceedings of the 8th Meeting on Supercritical Fluids. Bordeaux, France, Tome I, pp. 321-326.

Gil A., 2001. Recherche de complexation entre une nouvelle entité chimique et des cyclodextrines par co-broyage et malaxage. Ph.D. of the Paris XI University.

Gil, A., Chamayou, A., Leverd, E., Bougaret, J., Baron, M., Couarraze, G., 2004. Evolution of the interaction of a new chemical entity, Eflucimibe with $\gamma$-cyclodextrin during kneading process. Eur. J. Pharm. Sci. 23, 123-129.

Giordano, F., Novak, C., Moyano, J.R., 2001. Thermal analysis of cyclodextrins and their inclusion compounds. Thermochim. Acta 380, $123-151$. 
Junquero, D., Bruniquel, F., N'Guyen, X., Autin, J.-M., Patoiseau, J.F., Degryse, A.-D., Colpaert, F.C., Delhon, A., 2001. F 12511, a novel ACAT inhibitor, and atorvastatin regulate endogenous hypercholesterolemia in a synergistic manner in New Zealand rabbits fed a casein-enriched diet. Atherosclerosis 155, 131142.

Lochard, H., Rodier, E., Sauceau, M., Letourneau, J.-J., Fages, J., 2002. Particle generation by SAS process: effect of operating conditions on the specific surface area of the powder. In: Besnard, M., Cansell, F. (Eds.), Proceedings of the 8th Meeting on Supercritical Fluids. Bordeaux, France, Tome I, pp. 109-114.

Loftsson, T., Masson, M., 2001. Cyclodextrins in topical drug formulation: theory and practice. Int. J. Pharm. 225, 15-30.

Mullin, J.W., 1992. Crystallization, third rev. ed. Butterworth-Heinemann, Oxford.

Peng, D.-Y., Robinson, D., 1976. A new two-constant equation of state. Ind. Eng. Chem. Fundam. 15, 59-64.

Ribet, J.-P., Pena, R., Chauvet, A., Patoiseau, J.-P., Autin, J.-M., Segonds, R., Basquin, M., Autret, J.-M., 2002. Polymorphisme cristallin de l'Eflucimibe. Polymorphisme cristallin et medicament. Ann. Pharm. Fr. 60 (3), 177-186.

Sauceau, M., Letourneau, J.-J., Richon, D., Fages, J., 2003. Enhanced density-based models for solid compound solubilities in supercriti- cal carbon dioxide with cosolvents. Fluid Phase Equilib. 208, 99113.

Sauceau, M., Letourneau, J.-J., Freiss, B., Richon, D., Fages, J., 2004. Solubility of Eflucimibe in supercritical carbon dioxide with or without co-solvent. J. Supercrit. Fluids 31, 133-140.

Sertsou, G., Butler, J., Scott, A., Hempenstall, J., Rades, T., 2002. Factors affecting incorporation of drug into solid solution with HPMCP during solvent change co-precipitation. Int. J. Pharm. 45, 108-299.

Stella, J.V., Rajewski, R.A., 1997. Cyclodextrins: their future in drug formulation and delivery. Pharm. Res. 14 (5), 556-567.

Van Hees, T., Piel, G., Evrard, B., Otte, X., Thunus, L., Delattre, L., 1999. Application of supercritical carbon dioxide for the preparation of a piroxicam beta-cyclodextrin inclusion compound. Pharm. Res. 16 (12), 1864-1870

Van Hees, T., Piel, G., Henry De Hassonville, S., Evrard, B., Delattre, L., 2002. Determination of the free/included piroxicam ratio in cyclodextrin complexes: comparison between UV spectrophotometry and differential scanning calorimetry. Eur. J. Pharm. Sci. 15, 347-353.

Wiebe, R., Gaddy, V.L., 1941. Vapor phase composition of carbondioxide-water mixtures at various temperaturess and at pressures to 700 atmospheres. J. Am. Chem. Soc. 63, 475-477.

Yalkowsky, S.H., 1999. Solubility and solubilization in aqueous media. Oxford University Press. 